\title{
Chemical Synthesis, Efficacy, and Safety of Antimalarial Hybrid Drug Comprising of Sarcosine and Aniline Pharmacophores as Scaffolds
}

\author{
Jean Baptiste Niyibizi (iD, ${ }^{1,2}$ Peter G. Kirira, ${ }^{3,4}$ Francis T. Kimani, ${ }^{4}$ Fiona Oyatsi, ${ }^{3,5}$ \\ and Joseph K. Ng'ang'a ${ }^{1,5}$ \\ ${ }^{1}$ Pan African University Institute of Sciences, Technology and Innovation, Department of Molecular Biology and Biotechnology, \\ Nairobi, Kenya \\ ${ }^{2}$ University of Global Health Equity, MBBS/Basic Medical Sciences Division, Butaro/Kigali, Rwanda \\ ${ }^{3}$ Mount Kenya University, Department of Physical Chemistry, Nairobi, Kenya \\ ${ }^{4}$ Kenya Medical Research Institute, Nairobi, Kenya \\ ${ }_{5}^{5}$ Jomo Kenyatta University of Agriculture and Technology, School of Biomedical Sciences, Biochemistry Department, \\ Nairobi, Kenya
}

Correspondence should be addressed to Jean Baptiste Niyibizi; niyibizi3@gmail.com

Received 10 July 2019; Accepted 27 January 2020; Published 9 April 2020

Academic Editor: Sukla Biswas

Copyright (C) 2020 Jean Baptiste Niyibizi et al. This is an open access article distributed under the Creative Commons Attribution License, which permits unrestricted use, distribution, and reproduction in any medium, provided the original work is properly cited.

Malaria is a disease caused by protozoans transmitted to humans by infected female Anopheles mosquitoes. According to the WHO report of 2015, there were 214 million cases of malaria with 438,000 deaths worldwide. Ninety percent of world's malaria cases occur in Africa, where the disease is recognized as a serious impediment to economic and social development. Despite advancement in malaria research, the disease continues to be a global problem, especially in developing countries. Currently, there is no effective vaccine for malaria control. In addition, although there are effective drugs for treatment of malaria, this could be lost to the drug resistance in different Plasmodium species. The most lethal form is caused by P. falciparum which has developed resistance to many chemotherapeutic agents and possibly to the current drugs of choice. Reducing the impact of malaria is a key to achieving the sustainable development goals which are geared toward combating the disease. Covalent bitherapy is a rational and logical way of drug design which entails joining a couple of molecules with individual intrinsic action into a unique agent, hence packaging dual activity into one hybrid. This suggests the need to develop new antimalarial drugs that are effective against malaria parasites based on the new mode of action, molecular targets, and chemical structures. In silico studies have shown that sarcosine is able to bind to unique plasmodia proteins ( $P$. falciparum ATCase), whereas aniline can be a ligand to target protein (enoyl acyl carrier protein reductase), hence suppressing the progression of the disease. The main objective of this study was to synthesize and determine the efficacy and safety of antiplasmodial hybrid drug comprising the sarcosine and aniline derivative for management of plasmodial infections. The hybrid drug was synthesized by adding thionyl chloride to sarcosine to form acyl chloride which was then added to aniline to form sarcosine-aniline hybrid molecule. The IC50 of sarcosine-aniline hybrid was $44.80 \pm 4.70 \mathrm{ng} / \mathrm{ml} \mathrm{compared} \mathrm{with} \mathrm{that} \mathrm{of}$ aniline derivative which was $22.86 \pm 1.26 \mathrm{ng} / \mathrm{ml}$. The IC50 of control drugs was $2.63 \pm 0.38 \mathrm{ng} / \mathrm{ml}$ and $5.69 \pm 0.39 \mathrm{ng} / \mathrm{ml}$ for artesunate and chloroquine, respectively. There was a significant difference between IC50 of sarcosine-aniline hybrid and aniline derivative $(p<0.05)$. There was also a significant difference between sarcosine-aniline hybrid and standard drugs used to treat malaria including artesunate and chloroquine $(p<0.05)$. The ED50 of sarcosine-aniline hybrid drug was $6.49 \mathrm{mg} / \mathrm{kg}$ compared with that of aniline derivative which was $3.61 \mathrm{mg} / \mathrm{kg}$. The ED50 of control drugs was $3.56 \mathrm{mg} / \mathrm{kg}, 2.94 \mathrm{mg} / \mathrm{kg}$, and $1.78 \mathrm{mg} / \mathrm{kg}$ for artesunate-aniline hybrid, artesunate, and chloroquine, respectively. There was a significant difference $(p<0.05)$ between ED50 of sarcosine-aniline hybrid and both controls such as aniline derivative, artesunate, artesunate-aniline hybrid, and chloroquine. Cytotoxicity results revealed that sarcosine-aniline hybrid was safe to vero cells with a CC50 of $50.18 \pm 3.53 \mu \mathrm{g} / \mathrm{ml}$. Sarcosine-aniline hybrid was significantly less toxic compared with artesunate, chloroquine, and doxorubicin. Sarcosine-aniline hybrid was efficacious and safe to mice. Therefore, covalent bitherapy should be used in drug development for drug resistance mitigation. 


\section{Background}

Globally, malaria transmission occurs in five WHO regions. It is estimated that 3.2 billion people in 95 countries and territories are at risk of being infected with plasmodium species and developing disease (Figure 1), and 1.2 billion are at high risk, where more than 1 in 1000 people have chance of getting malaria in a year. Results from the World Malaria Report of 2015 show that malaria cases were ranging between 149 and 303 million or with an average of 214 million cases of malaria globally. The African region accounted for most global cases of malaria (88\%), followed by the Southeast Asian region (10\%) and the eastern Mediterranean region $(2 \%)$. In addition, the number of people who died from malaria was in the range of 236, 000 to 635, 000, representing an average of 438000 malaria deaths. The high burden was heaviest in the WHO African region (Figure 1), where an estimated $90 \%$ of all malaria deaths usually occur (Figure 1), and in children aged under 5 years, who accounted for more than two-thirds of all deaths [1]. This is because children of this age-group are highly susceptible to infection, illness than adults [2]. From the year 2000, malaria incidence rates decreased by $37 \%$ globally and by $42 \%$ in Africa, whereas malaria mortality rates went down by $66 \%$ in the African region and by $60 \%$ globally (Figure 1) [1].

Chemotherapy has been the backbone of malaria control strategy [3]. The Plasmodium species that are considered responsible for malaria in humans are $P$. vivax, $P$. falciparum, $P$. ovale, $P$. malariae, and $P$. knowlesi [4]. However, $P$. falciparum, the parasite that causes over $90 \%$ of all global malaria cases is more frequently becoming resistant to classical antimalarials, necessitating an urgent need for research and synthesis of new antimalarial agents, preferably with novel mode of action [3]. In the past two decades, only a few compounds belonging to a new class of antimalarial drugs, including aminoalcohols such as mefloquine, halofantrine, and lumefantrine; sesquiterpene trioxanes such as artemisinin derivatives; and naphthoquinones such as atovaquone were developed for clinical usage [5]. Currently, artemisinin-based combination therapy (ACT) is considered as the gold standard against $P$. falciparum, in which the regimen uses a double combination therapy geared toward delay of resistance, or preventing it altogether. Many approaches to antimalarial drug discovery deployed include optimization of therapy with available drugs such as combination therapy, developing analogs of the existing drugs, evaluation of potent agents from natural products especially plants, use of compounds originally developed against other diseases, evaluation of drug-resistance reversers (chemosensitizers), and new chemotherapeutic targets [3].

Currently, chemotherapy is the most important strategy to treat and prevent malaria. However, reports from Southeast Asia indicate parasite resistance to artemisinin based combination therapy, which is considered as the gold standard in treatment of malaria according to the WHO [6]. This suggests the need to develop new antimalarial drugs that are effective against malaria parasite based on a new mode of action, molecular targets, and chemical structures. In silico studies have shown that sarcosine $(\mathrm{N}-$ methyl glycine) is able to bind to unique plasmodia proteins, hence inhibiting parasite growth. In addition, it was shown that 3-chloro-4-(4-chlorophenoxy) aniline (aniline derivative) can bind to $P$. $f$ ENR (enoyl acyl carrier protein reductase), an enzyme which catalyzes the last step of the elongation cycle in the biosynthesis of fatty acids [7], thereby inhibiting the parasite growth. Nevertheless, no experimental study has been conducted to confirm this aspect of the two to have antiplasmodial activity singly or in a hybrid molecule.

Figure 1 shows that most of the malaria cases occur in Africa followed by Southeast Asia and Latin America. From the same figure, it is also shown that malaria has been eradicated in the USA and Europe. Sarcosine and aniline were suggested to have antiplasmodial activity based on bioinformatics studies. Covalent linking of sarcosine and aniline can carry a dual activity with different modes of action for inhibiting plasmodial growth. Based on the urgent need in drug development, it was necessary to validate this claim in this study. The expected outcome was that sarcosine-aniline hybrid could contain the dual activity of inhibiting the pyrimidine and fatty acid biosynthesis, which might circumvent the parasite resistance to ACTs. Chemical structures of sarcosine and aniline are shown in Figure 2.

\section{Methods}

2.1. Study Design. This project was a laboratory-based experimental study carried out at the Kenya Medical Research Institute (KEMRI), Centre for Biotechnology Research and Development (CBRD), Malaria Unit in Collaboration with the Center For Virology Research (CVML) and Center for Traditional Medicine Drugs and Research (CTMDR).

2.2. Sources of Chemicals. Sarcosine, aniline, thionyl chloride, dichloromethane, magnesium sulfate, and ammonium chloride, thin layer chromatography (TLC) plates, hypoxanthine, dimethyl sulfoxide, and other supplies were provided by Sigma Aldrich company.

\subsection{Chemical Synthesis: Procedure for Coupling Aniline to} Sarcosine. Thionyl chloride $(1.5 \mathrm{~mL}, 20 \mathrm{mmol})$ was added to sarcosine $(0.09 \mathrm{~g}, 1.0 \mathrm{mmol})$, and the resulting suspension was refluxed for 6 hours to give a clear yellow solution. Excess thionyl chloride was removed in vacuo, and the acid chloride was dissolved in dry dichloromethane $\left(\mathrm{CH}_{2} \mathrm{Cl}_{2}\right)$ $(10 \mathrm{~mL})$ and cooled to $0^{\circ} \mathrm{C}$. A solution of 3-chloro-4-(4chlorophenoxy) aniline $(4.0 \mathrm{mmol})$ and triethylamine $(0.20 \mathrm{~mL}, 2.0 \mathrm{mmol})$ in dry $\mathrm{CH}_{2} \mathrm{Cl}_{2}(2.5 \mathrm{~mL})$ was added via a cannula. The resulting mixture was stirred at room temperature for 16 hours during which time a white precipitate was formed. The suspension was washed with half-saturated aqueous ammonium chloride solution $(2 \times 6 \mathrm{~mL})$ and water $(2 \times 3 \mathrm{~mL})$, then dried over anhydrous magnesium sulphate $\left(\mathrm{MgSO}_{4}\right)$, and concentrated in vacuo. The formation of a hybrid molecule was monitored by thin layer chromatography (TLC). 
Countries with indigenous cases in 2000 and their status by 2017 Countries with zero indigenous cases over at least the past 3 consecutive years are considered to be malaria free. All countries in the WHO European Region reported zero indigenous cases in 2016 and again in 2017. In 2017, both China and EI Salvador reported zero indigenous cases. Source: WHO database.

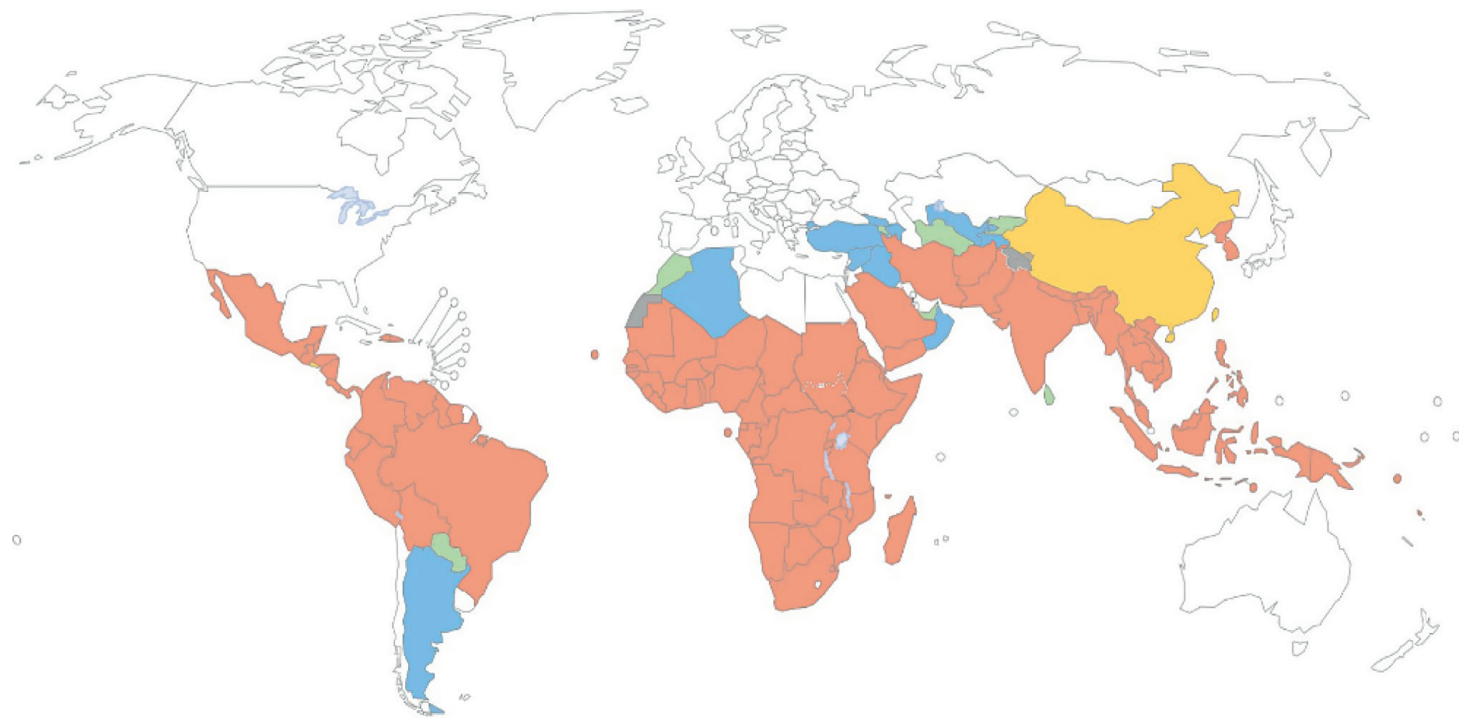

WHO: World Health Organization.

One or more cases in 2017

Zero cases in 2017

Zero cases ( $\geq 3$ years) in 2017

Certified malaria free since 2000
No malaria
Not applicable

FIgURE 1: Global distribution of malaria throughout the world (source: World Malaria Report 2018) [1].<smiles>Nc1ccc(Oc2ccc(Cl)cc2)c(Cl)c1</smiles><smiles>CNCC(=O)O</smiles>

Sarcosine

FIGURE 2: Structure of aniline and sarcosine.

The sarcosine-aniline hybrid drug was synthesized by coupling sarcosine to aniline as shown in the following reactions.

Figure 3 shows the reaction between sarcosine and thionyl chloride in dichloromethane solvent to form acyl chloride. This reaction is irreversible because $\mathrm{SO}_{2}$ and $\mathrm{HCl}$ gasses are lost in the reaction mixture.

Figure 4 illustrates the reaction between acyl chloride and aniline to form sarcosine-aniline hybrid at room temperature. In this reaction, there is a nucleophilic substitution of $\mathrm{Cl}$ by $\mathrm{NH}_{2}$. The formation of sarcosine-aniline hybrid was spotted on thin layer chromatography and observed as band under UV light (Figure 5).

2.4. Thin Layer Chromatography Procedure. TLC was run by spotting the sarcosine-aniline hybrid on the TLC plate in a solvent system of ethyl acetate $(2 \mathrm{ml})$. The plate was dried to observe and take a photo of the spot, in a small container that has a lid mix of about $4 \mathrm{~g}$ of silica gel and $1 \mathrm{~g}$ of iodine crystals. The TLC plate was placed in the mixture and shook gently to get in contact with the TLC plate for 5 minutes. The plate was taken to fluorescent machine under UV to observe dark spots of aniline and sarcosine-aniline hybrid. After TLC experiment, the location of each spot on the plate was represented by calculating its retention factor (Rf). The retention factor (Rf) was calculated by dividing the distance travelled by the compound by the distance from the baseline to the solvent front [8].

$$
\mathrm{Rf}=\frac{\text { distance spot moved }}{\text { distance solvent moved }} \text {. }
$$

Figure 5 shows the results of sarcosine-aniline hybrid formation on the thin layer chromatography plate. EtOAc stands for ethyl acetate, and the solvent system used to run this TLC consisted only of EtOAc (100\% concentrated). Aniline was used as a control in the middle of the plate (second column). From the left to right, for the first and third column, the first spots closer to the base line of the columns is 3-chloro-4-(4-chlorophenoxy) aniline, then the spots closer to the top are sarcosine-aniline hybrid. The sarcosine-aniline hybrid is less polar than 3-chloro-4(4-chlorophenoxy) aniline, so it would elute (released) faster than 3-chloro-4-(4-chlorophenoxy) aniline. The 


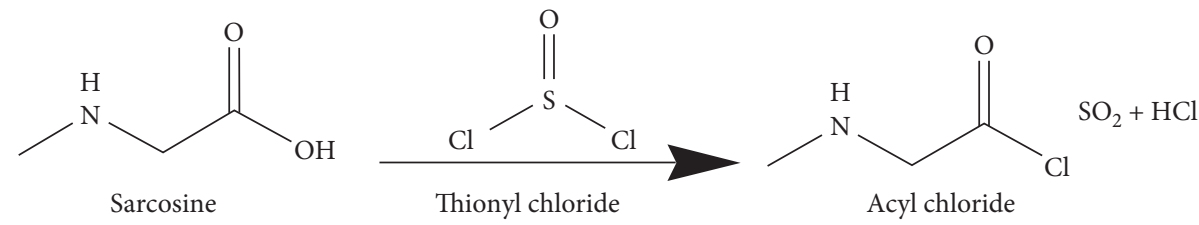

Figure 3: Reaction between sarcosine and thionyl chloride.

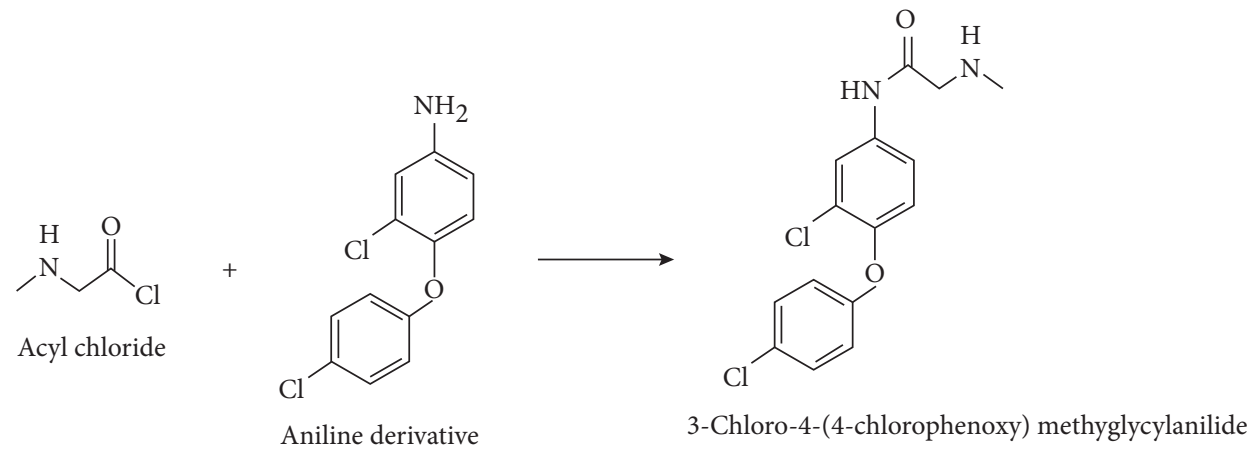

FIgURE 4: Coupling acyl chloride to aniline.

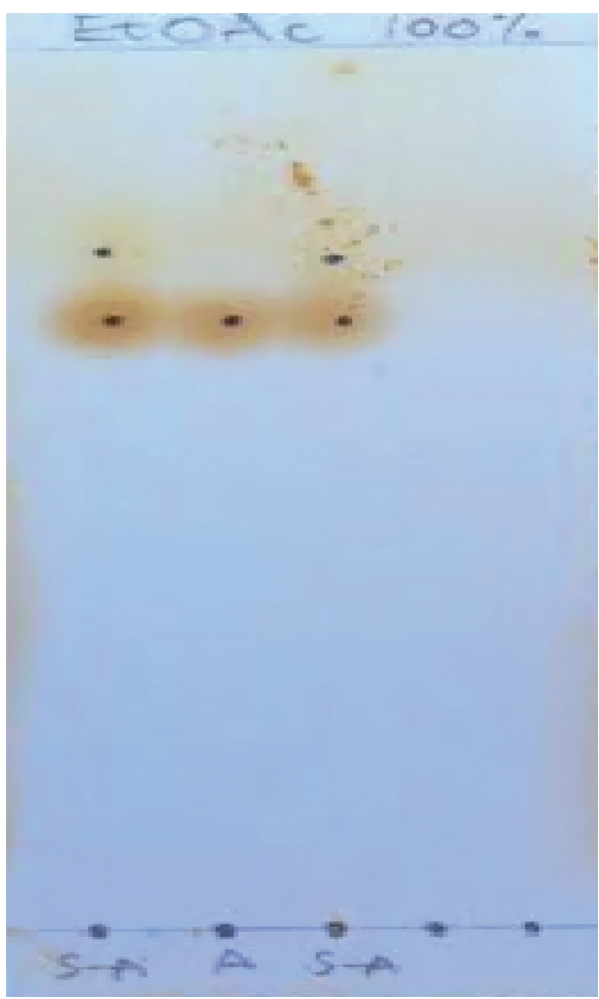

FIGURE 5: Thin layer chromatography results

retention factor (Rf) value for the sarcosine aniline hybrid (S-A) was $4.4 / 5.8=0.76$, and the $\mathrm{Rf}$ of aniline was 4 / $5.8=0.69$.

\subsection{In Vitro Bioassays}

2.5.1. Drug Solutions and Plasmodium falciparum Cultures. Stock solution of the test compound and reference drugs was prepared with sterile water (deionized and autoclaved). The drugs which were insoluble in water were enhanced by first dissolving them in dimethylsulfoxide (solvent concentration $<0.02 \%)$. The test samples were prepared as a $10 \mathrm{mg} \cdot \mathrm{ml}^{-1}$ stock solution. Further dilutions were prepared on the day of biological assays. All the drug solutions were stored at $4^{\circ} \mathrm{C}$ for later use.

Laboratory-adapted $P$. falciparum strains isolates 3D7 (CQ sensitive) were used in this study. The strains were grown and maintained at the Kenya Medical Research Institute, malaria laboratory. Sterile tissue culture flasks were used which contained complete medium with $1 \%$ cell suspension at different initial parasitaemia. The culture medium consisted of RPMI 1640 supplemented with $10 \%$ human serum, $25 \mathrm{mM}$ N-2-hydroxyethylpiperazine-N-2ethanesulfonic acid (HEPES), and $25 \mathrm{mM} \mathrm{NaHCO}_{3}$ [9]. Human type $\mathrm{O}+$ erythrocytes ( $<28$ days old), obtained from healthy volunteers after ethical approval and obtaining consent from the participants, served as host cells. The volunteer read and complete the questionnaire of blood donation for in vitro $P$. falciparum cultures which were kept in CBRD/malaria unit and remained private and confidential for each volunteer. The donor was acceptable when he/she is not taking antibiotics or antimalarial drugs. In addition, the blood was tested for HIV and hepatitis antigens at the Center for Virology Research, from which positive samples were immediately incinerated. The accepted blood samples were stored at $4^{\circ} \mathrm{C}$ in a fridge. The cultures were incubated at $37^{\circ} \mathrm{C}$ in an atmosphere of $3 \%$ $\mathrm{CO}_{2}, 5 \% \mathrm{O}_{2}$, and $92 \% \mathrm{~N}_{2}$.

2.5.2. In Vitro Drug Sensitivity Studies. For measuring the antiplasmodial activity, aliquots $(25 \mu \mathrm{L})$ of the culture medium were added to all the wells of a 96-well microculture plate. The hybrid drug solution in volumes of $25 \mu \mathrm{L}$ were added in triplicate, to the first well, and then the serial 
dilution was carried out to the following wells to make serial dilutions of each sample over an 11-fold concentration range from the highest concentration of $100 \eta \mathrm{g} \cdot \mathrm{ml}^{-1}$ to $0.0975 \eta \mathrm{g} \cdot \mathrm{ml}^{-1}$. The same procedure was carried out for reference drugs such as artesunate and chloroquine [10].

The quantitative evaluation of antimalarial activity in vitro was carried out by using a semiautomated microdilution technique known as tritiated hypoxanthine incorporation assay (THA). Radiolabeled hypoxanthine uptake by the parasite is an indicator of its growth and multiplication. This method helped to determine the antimalarial drug activity against the intraerythrocytic asexual stage of $P$. falciparum grown in the in vitro culture [11].

For each microwell solution, $25 \mu \mathrm{l}$ of $\left[{ }^{3} \mathrm{H}\right]$ hypoxanthine was added, and the reaction was allowed to take place for 48 hours of incubation at $37^{\circ} \mathrm{C}$. In this method, the amount of tritiated hypoxanthine, which is incorporated into parasite DNA, was determined by the scintillation counting method. Thus, the determination of labeled tritium hypoxanthine inserted into parasite DNA during replication might be used to define parasite drug susceptibility [11]. After 48 hours of incubation, the parasites were harvested using harvesting machine, and measurement of radioactivity was performed by scintillation counter machine (Wallac1450 Microbeta reader). Mean counts per minute $(\mathrm{cpm})$ are generally in the range of 20,000-60,000, with an acceptable minimum of 10,000 [12].

$\%$ reduction in $3 \mathrm{H}$ Hypoxanthine uptake

$$
=100 * \frac{\text { gm of no drug sample }- \text { gm of test samples }}{\text { gm of no drug sample }}
$$

where gm refers to geometric mean cpm (counts per minute) [12].

Percent reductions in ${ }^{3} \mathrm{H}$ Hypoxanthine uptake was used to plot percentage inhibition of growth as a function of drug concentration. $\mathrm{IC}_{50}$ activity was determined by linear regression analyses on the linear segments of the dose response curve.

\subsection{In Vivo Bioassays}

2.6.1. Experimental Animals and Parasites. Female Swiss albino mice were collected and kept in the animal house of the Center for Biotechnology and Research Development at the Kenya Medical Research Institute (KEMRI), where the animal experiments were carried out. The animals were six weeks old, weighing 20 to $22 \mathrm{~g}$, and they were kept in mice cages and were allowed to access mice pencils (Ungafeed Company Ltd) and water before experimental testing. Plasmodium berghei ANKA strains, sensitive to quinolone and artemisinin-based drugs, were obtained from the Unit of Malaria, Center for Biotechnology and Research and Development, Kenya Medical Research Institute. Parasites were maintained and cryopreserved in a freezer $\left(-80^{\circ} \mathrm{C}\right)$. The parasite was subsequently maintained in the laboratory by serial blood passage from mouse to mouse on a weekly basis.
2.6.2. Procedure for In Vivo Efficacy of Sarcosine-Aniline Hybrid. This consisted of in vivo evaluation of hybrid drug against $P$. berghei ANKA, a rodent parasite which is commonly used in antimalarial studies [13]. Female Swiss albino donor mouse was injected intraperitoneally with $0.2 \mathrm{ml}$ of inoculums of $1 \times 10^{7}$ parasitized erythrocytes, and $P$. berghei ANKA strain was obtained from the donor mouse [14]. Parasitaemia was assessed after 5 days under microscope using the Giemsa staining technique. The donor mouse was sedated using carbon dioxide to collect blood via cardiac puncture in a heparinized tube using a syringe and a needle. Carcasses were pooled in a biohazard container and stored at room temperature while waiting to be incinerated. Afterward, the experimental mice were infected with inoculums of $1 \times 10^{7}$ parasitized erythrocytes using an intraperitoneal method. The mice were grouped into five groups consisting of 5 mice per group. The sarcosine-aniline hybrid was dissolved in $10 \%$ of Tween 80 , and oral drug was administered daily for 4 days. Blood for making thin blood smear was collected from the tip of the mouse tail. The efficacy of the drug was measured by comparison of blood parasitaemia after the four days of therapy (i.e., on day 5 postinfection). The ones still alive at the end of the experiments were killed by using carbon dioxide gas followed by incineration.

The determination of the dose to be administered was calculated individually according to each mouse weight. In this regard, these formulas were applied: $\operatorname{HED}(\mathrm{mg} / \mathrm{kg})=$ Animal Dose $(\mathrm{mg} / \mathrm{kg}) *$ [Animal $\mathrm{km} /$ Human $\mathrm{km}$ ], where HED stands for human equivalent dose and $\mathrm{km}$ which is a conversion factor. With $\mathrm{km}$ (a constant)=Weight $/$ Body surface area. For mice of $0.02 \mathrm{~kg}$, with a body surface area of $0.007, \mathrm{~km}=0.02 / 0.007=3[15]$.

$$
\text { Dosage }(\mathrm{mg} / \mathrm{kg})=\frac{\text { Drug concentration }(\mathrm{mg} / \mathrm{ml}) * \text { Volume }(\mathrm{ml})}{\text { Body weight }(\mathrm{kg})} \text {. }
$$

From formula (2) [16],

Volume (ml) of drug to be given to each mouse

$$
=\frac{\text { Body weight }(\mathrm{kg}) * \text { Dosage }(\mathrm{mg} / \mathrm{kg})}{\text { Drug concentration }(\mathrm{mg} / \mathrm{ml})} \text {. }
$$

Administration of the dose for testing drugs and reference drugs (artesunate and chloroquine) to assess the treatment of the experimental groups had been carried out using an oral method by administering $0.2 \mathrm{ml}$ of infected blood with varying dosages of $10,5,2.5,1.25$, and $0.625 \mathrm{mg} \cdot \mathrm{kg}^{-1}$. The control groups had been given the normal saline alongside testing using the same procedure. The parasitaemia was checked for every 24 hours from the time of infection for 4 days. Thin blood smears were prepared from each mouse tail venous blood. The smears were prepared by the Giemsa staining technique, and the parasitaemia of individual mouse had been checked using a light microscope [12]. The following formula was used to calculate the percentage parasitaemia [12]: 
The Percentage of parasitaemia

$$
=\frac{\text { Number of parasitized RBCs/field }}{\text { Total number of RBCs/field }} * 100 \text {. }
$$

After 4 days, the percentage (\%) chemosuppression of each drug was determined using the following formula [17]:

$$
\text { Percentage chemosuppression }=100-\left[\left(\frac{A-B}{A}\right) \times 100\right] \text {, }
$$

where $A$ is the mean parasitaemia in the negative control group and $B$ is the parasitaemia in the test group. The dose that cured $50 \%$ of infected animals had been determined as effective dose $\left(\mathrm{ED}_{50}\right)$ using a nonlinear regression logistic dose-response model.

\subsection{Cytotoxicity Assays}

2.7.1. Preparation of Drug Solutions and Culture of Vero Cells Used in Cytotoxicity Study. To conduct in vitro toxicity, stock solutions of the test compound and reference drugs were prepared with sterile water. The drugs which were insoluble in water had their solubility been enhanced by first dissolving $10 \mathrm{mg}$ in $100 \mu \mathrm{l}$ of $100 \%$ dimethyl-sulfoxide. The test samples were prepared as a $1 \mathrm{mg} \cdot \mathrm{ml}^{-1}$ stock solution. Further dilutions were prepared on the day of biological assays. All the drug solutions were stored at $4^{\circ} \mathrm{C}$ for later use. Vero cells (Vero E-6) were obtained from the Center for Traditional Medicine Drugs and Research (CTMDR), KEMRI. Vero cells are kidney cells extracted from an African green monkey (Cercopithecus aethiops). They were stored in a nitrogen tank $\left(-191^{\circ} \mathrm{C}\right)$ in the biology department, CTMDR, KEMRI. Cells were maintained in Minimum Essential Eagle's Medium (MEM) containing 10\% fetal bovine serum (FBS), PenStrep, and glutamine. Vero cells were cultured using T-75 culture flasks. The flasks were kept at $37^{\circ} \mathrm{C}$ in $5 \% \mathrm{CO}_{2}$, and the cells were passaged every 2 to 3 days to keep the cells alive. Trypsinization was carried out to detached cells which overlap each other and counted using a hemocytometer (Neubauer).

2.7.2. Procedure for Cytotoxicity Assay. Using a 96microwell plate, a cell density of 20,000 vero cells were seeded and incubated for 24 hours at $37^{\circ} \mathrm{C}$ under $5 \% \mathrm{CO}_{2}$ to allow cells to attach to the surface/base of the plate. Sarcosine-aniline hybrid drug as the test drug, and controls were added in triplicate to the cultured cells in a concentration range $100 \mathrm{ug} / \mathrm{ml}$, and subsequent dilutions were carried out over 7 folds, from 100, 50, 25, 12.5, 6.25, $3.125,1.5625$, to $0.78125 \mu \mathrm{g} / \mathrm{ml}$. The plates were incubated for 48 hours at $37^{\circ} \mathrm{C}$ under $5 \% \mathrm{CO}_{2}$ to allow the reaction to occur. After 48 hours, $0.5 \mathrm{mg} / \mathrm{ml}$ of 3-(4, 5-dimethylthiazol-2-yl)-2,5-diphenyltetra-zolium bromide (MTT) was added for calorimetric measurement of the ability of a drug to kill the vero cell lines [18]. The plates were incubated at $37^{\circ} \mathrm{C}$ for 3 hours. $100 \mu \mathrm{L}$ of $100 \%$ DMSO was added to each well and mixed to ensure cell lysis and dissolving of the formazan crystals. Doxorubicin was used as a control drug.

Optical density was read using Multi Skan Ex reader machine 48X, from Thermo Fisher Scientific company in a UV-visible spectrophotometry at 562 and $690 \mathrm{~nm}$. The amount of formazan measured was directly proportional to the number of viable cells. The results were recorded as optical density (OD) per well at each drug concentration and analyzed using Microsoft Excel software 2010, from which the percentage of cytotoxicity (PC) was calculated using the following equation: Percentage cytotoxicity $=[(A-B) / A] \times$ 100 [19]. where $A$ is the mean OD of untreated cells and $B$ is the mean $\mathrm{OD}$ at each drug concentration. The drug concentration that leads to $50 \%$ inhibition of cell growth $\left(\mathrm{CC}_{50}\right)$ was determined by the nonlinear regression logistic doseresponse model.

The end points of the mouse experiment in the in vivo assays were set to consider with the development of the clinical signs such as impaired ambulation which prevents animals from reaching for food or water, excessive weight loss and extreme emaciation, lack of physical or mental alertness, difficult labored breathing, and prolonged inability to remain upright. To avoid severe and enduring distress, mice that showed those clinical signs were euthanized by passing carbon dioxide gas into a closed chamber and then incinerating.

2.8. In Vivo Toxicity Studies. In this step, acute toxicity was performed. Three dosages, such as $2000 \mathrm{mg} \cdot \mathrm{kg}^{-1}$, and $300 \mathrm{mg} \cdot \mathrm{kg}^{-1}$, and $50 \mathrm{mg} / \mathrm{kg}$ were administered orally to mice in three groups, and the fourth group which served as a control received water as a placebo. Each group consisted of 3 mice, and the weight and number of dead mice were monitored and recorded after each 4 days over an interval of 14 days. Clinical or physical signs were also subjected to be recorded during the study period. At the end of the experiment, the mice were killed by using concentrated carbon dioxide gas followed by incineration. The number of dead mice was to be recorded, and a semilog plot of log concentration against percentage (\%) response was made. The dose that was to kill $50 \%$ of the mice will was to be called LD50 (lethal death) [20], and from this, we can deduce the therapeutic index $=$ LD50/ED50.

\section{Results}

\subsection{In Vitro Activity of Sarcosine-Aniline Hybrid}

3.1.1. In Vitro Activity of 3-Chloro-4(4-chlorophenoxy) Methyglycylanilde. Table 1 shows the activity of the drug which inhibits the growth of P. falciparum 3D7 strains, CQ sensitive. The $\mathrm{IC}_{50}$ of sarcosine-aniline hybrid was $44.80 \mathrm{ng} / \mathrm{ml}$. Sarcosine did not show in vitro activity. Table 1 also describes the comparisons of $\mathrm{IC}_{50}$ of sarcosine-aniline hybrid drug against artesunate, aniline, and chloroquine. There was a significant difference between the $\mathrm{IC}_{50}$ of sarcosine-aniline hybrid drug against aniline, artesunate, and chloroquine $(p<0.05)$. There was a significant difference between positive 
TABLE 1: $\mathrm{IC}_{50}$ of sarcosine-aniline hybrid versus control drugs on P. falciparum 3D7 strains.

\begin{tabular}{lccccc}
\hline & Drugs & IC & & \multicolumn{2}{c}{$p$ value } \\
& & & 1 & 2 & 3 \\
\hline 1 & Sarcosine-aniline hybrid drug & $44.80 \pm 4.70 \mathrm{ng} / \mathrm{ml}$ & & $p \leq 0.001^{*}$ & $p \leq 0.001^{*}$ \\
2 & Aniline & $22.86 \pm 1.26 \mathrm{ng} / \mathrm{ml}$ & $p \leq 0.001^{*}$ & & $p \leq 0.001^{*}$ \\
3 & Artesunate & $2.63 \pm 0.38 \mathrm{ng} / \mathrm{ml}$ & $p \leq 0.001^{*}$ & $p \leq 0.001^{*}$ & $p \leq 0.001^{*}$ \\
4 & Chloroquine & $5.69 \pm 0.39 \mathrm{ng} / \mathrm{ml}$ & $p \leq 0.001^{*}$ & $p \leq 0.001^{*}$ & 0.46 \\
5 & Sarcosine & No activity & & & \\
\hline
\end{tabular}

*Significant: $p<0.05$. In this table, 1: sarcosine-aniline hybrid drug, 2: aniline, 3: artesunate, 4: chloroquine, and 5: sarcosine.

controls (artesunate and chloroquine) and aniline. However, there was no significant difference between artesunate and chloroquine $(p>0.05)$.

3.2. In Vivo Efficacy Studies. Figure 6 shows the percentage of chemosupression of parasitaemia for sarcosine-aniline hybrid, aniline derivative, artesunate, artesunate-aniline hybrid, and chloroquine after 4 days of oral treatment. The percentage of chemosupression for mice treated with $10 \mathrm{mg} / \mathrm{kg}$ of sarcosine-aniline hybrid was $52 \%$, whereas those treated with aniline was $68 \%$. No parasites were observed under the microscope for the mice treated with $10 \mathrm{mg} / \mathrm{kg}$ of artesunate and that of chloroquine.

Table 2 shows the effective dose of the drug which inhibits the growth of $P$. berghei ANKA sensitive strain to quinoline- and artemisinin-based drug parasites by $50 \%$ after four days of oral treatment. The $\mathrm{ED}_{50}$ of sarcosineaniline hybrid was $6.49 \mathrm{mg} / \mathrm{kg}$. Other drugs and compounds such as artesunate, artesunate-aniline hybrid, chloroquine, and sarcosine were used as controls. Sarcosine did not show in vivo activity.

Table 2 also describes the comparisons of $\mathrm{ED}_{50}$ of sarcosine-aniline hybrid drug against artesunate, artesunateaniline hybrid, aniline, and chloroquine. There was a significant difference between $\mathrm{ED}_{50}$ of sarcosine-aniline hybrid drug against artesunate, artesunate-aniline hybrid, and chloroquine $(p<0.05)$.

Table 3 shows the actual average of parasitaemia at days 7,9 , and 11 after stopping the treatment with $10 \mathrm{mg} / \mathrm{kg}$. The parasitaemia of sarcosine-aniline hybrid was $9.74 \%, 12.98 \%$, and $15.61 \%$ on days 7,9 , and 11 , respectively. The recrudescence of CQ and artesunate reappeared on day 9 with $0.03 \%$ and $0.2 \%$, respectively.

Table 4 shows the number of mice which survived up to 11 days of experiment, which is 7 days after stopping oral drug administration. For sarcosine-aniline hybrid, 3 mice among 5 survived in the groups which received $10 \mathrm{mg} / \mathrm{kg}$, and 2 mice survived in that group which received $5 \mathrm{mg} / \mathrm{kg}$, whereas only 1 mouse survived in the groups which received $2.5 \mathrm{mg} / \mathrm{kg}, 1.25 \mathrm{mg} / \mathrm{kg}$, and $0.625 \mathrm{mg} / \mathrm{kg}$. Up to day 11 , all mice which received $10 \mathrm{mg} / \mathrm{kg}$ of artesunate and chloroquine survived along in vivo efficacy testing.

\subsection{In Vivo Toxicity}

3.3.1. Acute Toxicity. Table 5 illustrates the number of dead mice during acute toxicity testing for 14 days. The three

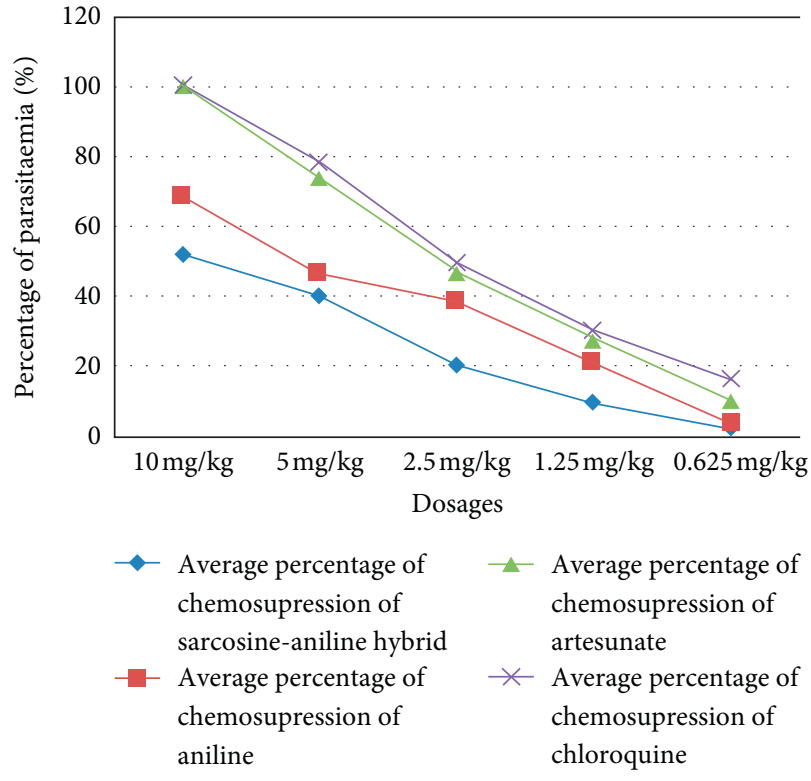

FIgURE 6: Percentage of parasitaemia chemosupression of sarcosine-aniline hybrid.

TABLE 2: $\mathrm{ED}_{50}$ of sarcosine-aniline hybrid versus control drugs on $P$. berghei ANKA.

\begin{tabular}{|c|c|c|c|c|c|c|c|c|}
\hline & \multirow{2}{*}{ Drugs } & \multirow{2}{*}{$\mathrm{ED}_{50}$} & \multicolumn{6}{|c|}{$p$ value } \\
\hline & & & 1 & 2 & 3 & 4 & 5 & 6 \\
\hline 1 & $\begin{array}{l}\text { Sarcosine-aniline } \\
\text { hybrid drug }\end{array}$ & $6.49 \mathrm{mg} / \mathrm{kg}$ & & $p^{a}$ & 0.1 & $p^{a}$ & $p^{a}$ & $p^{\mathrm{a}}$ \\
\hline 2 & Aniline & $3.61 \mathrm{mg} / \mathrm{kg}$ & $p^{\mathrm{a}}$ & & $p^{a}$ & $p^{\mathrm{a}}$ & $p^{a}$ & $p^{\mathrm{a}}$ \\
\hline 3 & $\begin{array}{c}\text { Artesunate } \\
\text {-aniline hybrid }\end{array}$ & $3.56 \mathrm{mg} / \mathrm{kg}$ & $p^{a}$ & 0.1 & & $p^{a}$ & $p^{a}$ & $p^{\mathrm{a}}$ \\
\hline 4 & Artesunate & $2.94 \mathrm{mg} / \mathrm{kg}$ & $p^{\mathrm{a}}$ & 0.424 & $p^{a}$ & & $p^{\mathrm{a}}$ & $p^{\mathrm{a}}$ \\
\hline 5 & Chloroquine & $1.78 \mathrm{mg} / \mathrm{kg}$ & $p^{\mathrm{a}}$ & $p^{\mathrm{a}}$ & $p^{a}$ & $p^{\mathrm{a}}$ & & $p^{\mathrm{a}}$ \\
\hline 6 & Sarcosine & No activity & $p^{\mathrm{a}}$ & $p^{a}$ & $p^{a}$ & $p^{a}$ & $p^{a}$ & \\
\hline
\end{tabular}

groups of mice received different dosage $(2000 \mathrm{mg} / \mathrm{kg}$, $300 \mathrm{mg} / \mathrm{kg}$, and $50 \mathrm{mg} / \mathrm{kg}$ ) of sarcosine-aniline hybrid drug, and the control group did not receive any drug but water. For all groups, the initial weights ranged from 20 to $22 \mathrm{~g}$, and they were all females. No mouse died in all groups for 14 days.

3.3.2. Weights Changes and Physical Features during Acute Toxicity Experiment. The weight of each individual mouse in 
TABle 3: Parasitaemia growth of sarcosine-aniline hybrid after stopping treatment.

\begin{tabular}{lccc}
\hline Drugs & Day 7 & Day 9 & Day 11 \\
\hline Sarcosine-aniline hybrid & 9.74 & 12.98 & 15.61 \\
Aniline & 6.97 & 9.03 & 11.84 \\
Artesunate & 0.00 & 0.2 & 0.67 \\
CQ & 0.00 & 0.03 & 0.42 \\
\hline
\end{tabular}

Table 4: Survival rate after 11 days of in vivo efficacy testing.

\begin{tabular}{|c|c|c|c|c|c|c|}
\hline $\begin{array}{l}\text { Dosage } \\
(\mathrm{mg} / \mathrm{kg})\end{array}$ & $\begin{array}{c}\text { Sarcosine-aniline } \\
\text { hybrid }\end{array}$ & Sarcosine & $\begin{array}{l}\text { 3-Chloro-4-(4-chlorophenoxy) } \\
\text { aniline }\end{array}$ & Artesunate & $\begin{array}{l}\text { Artesunate-aniline } \\
\text { hybrid }\end{array}$ & Chloroquine \\
\hline 10 & 3 & 1 & 4 & 5 & 3 & 5 \\
\hline 5 & 2 & 2 & 2 & 3 & 2 & 4 \\
\hline 2.5 & 1 & 1 & 3 & 4 & 3 & 4 \\
\hline 1.25 & 1 & 1 & 3 & 3 & 3 & 3 \\
\hline 0.625 & 1 & 0 & 1 & 2 & 1 & 3 \\
\hline
\end{tabular}

Table 5: Acute toxicity in mice following different dosage administrations.

\begin{tabular}{lccc}
\hline Group & Dosage of hybrid drug administered orally $(\mathrm{mg} / \mathrm{kg})$ & Number of mice per group & Number of dead mice after 28 days \\
\hline Group 1 & 2000 & 3 & 0 \\
Group 2 & 300 & 3 & 0 \\
Group 3 & 50 & 3 & 0 \\
Control group & 0 & 3 & 0 \\
\hline
\end{tabular}

each group and the weight variation in for 14 days of acute toxicity testing were recorded. Three groups of mice received different dosage $(2000 \mathrm{mg} / \mathrm{kg}, 300 \mathrm{mg} / \mathrm{kg}$, and $50 \mathrm{mg} / \mathrm{kg}$ ) of sarcosine-aniline hybrid drug, and the control group did not receive any drug but water. The initial weights for all groups ranged from 20 to $22 \mathrm{~g}$, and they were all females. The weights were recorded after 4 days of intervals. The mean average of weight for the mice which received $2000 \mathrm{mg} / \mathrm{kg}$ was $21.34 \mathrm{~g}$ after 14 days. The mean average of weights for the mice which received $300 \mathrm{mg} / \mathrm{kg}, 50 \mathrm{mg} / \mathrm{kg}$, and mice in the control group were $21.58 \mathrm{~g}, 22.24 \mathrm{~g}$, and $22.33 \mathrm{~g}$, respectively, after 14 days of acute toxicity testing. There was no significant difference in weight changes between mice which received $200 \mathrm{mg} /$ $\mathrm{kg}, 300 \mathrm{mg} / \mathrm{kg}$, and $50 \mathrm{mg} / \mathrm{kg}$ and between the control groups $(\mathrm{p}>0.05)$. There was no critical physical manifestation of pain distress observed during acute toxicity period.

3.4. Cytotoxicity Results. Table 6 shows the $\mathrm{CC}_{50}$, Standard deviation (SD) of the mean of sarcosine-aniline hybrid drug against vero cells after triplicate experiments. 3(4,5-dimethylthiazol-2-yl)-2,5-diphenyltetrazolium bromide (MTT) assay was used which is based on the ability of a mitochondrial dehydrogenase enzyme from viable cells to cleave the tetrazolium rings of pale yellow MTT and thereby form dark blue formazan crystals which are largely impermeable to cell membranes, resulting in their accumulation within healthy cell cytoplasms. Chloroquine and artesunate were used as standard drugs which are used to treat malaria, whereas doxorubicin was used as a known cytotoxic drug. During experiment, the starting concentration (highest) for both drugs was $100 \mu \mathrm{g} / \mathrm{ml}$. Sarcosine-aniline hybrid showed a $\mathrm{CC}_{50}$ of $50.18 \mu \mathrm{g} / \mathrm{ml}$, while the $\mathrm{CC}_{50}$ of doxorubicin was $1.96 \mu \mathrm{g} / \mathrm{ml}$.

If $\mathrm{CC}_{50}$ of a drug is less than $2 \mu \mathrm{g} / \mathrm{ml}$, the drug is considered as cytotoxic, and when $\mathrm{CC}_{50}$ is $2-89 \mu \mathrm{g} / \mathrm{ml}$, the drug is considered as moderately cytotoxic, and when it is above $90 \mu \mathrm{g} / \mathrm{ml}$, the drug is considered as not cytotoxic (safe) [21].

Regarding $\mathrm{CC}_{50}$ of sarcosine-aniline hybrid drug against artesunate, chloroquine, and doxorubicin, there was a significant difference between the $\mathrm{CC}_{50}$ of sarcosine-aniline hybrid drug against chloroquine, artesunate, and doxorubicin $(p<0.05)$. The highest mean difference was observed between the $\mathrm{CC}_{50}$ of sarcosine-aniline hybrid and doxorubicin (48.21), whereas the lowest mean difference was observed between sarcosine-aniline hybrid and chloroquine $(-7.78)$.

3.5. Therapeutic Index of Sarcosine-Aniline Hybrid. The therapeutic index (TI) of drug is equal to its lethal dose concentration divided by its effective dose (LD50/ED50). The $\mathrm{LD}_{50}$ of sarcosine-aniline hybrid was estimated to be greater than $5000 \mathrm{mg} / \mathrm{kg}$, and its ED50 was $6.49 \mathrm{mg} / \mathrm{kg}$. Therefore, the therapeutic index of sarcosine-aniline hybrid drug was greater than 770.41 . 
TABLE 6: The $\mathrm{CC}_{50}$ values of the different antimalarial drugs against vero cells.

\begin{tabular}{|c|c|c|c|}
\hline SN & Drugs & Mean $\mathrm{CC}_{50}$ in $\mu \mathrm{g} / \mathrm{ml}$ & SD \\
\hline 1 & Sarcosine-aniline hybrid & 50.18 & 3.53 \\
\hline 2 & Chloroquine & 57.96 & 3.85 \\
\hline 3 & Artesunate & 19.69 & 3.26 \\
\hline 4 & Doxorubicin & 1.96 & 0.59 \\
\hline \multicolumn{4}{|c|}{ The $C C_{50}$ values of sarcosine-aniline hybrid versus other antimalarial drugs } \\
\hline SN & Cell type to be compared & Mean difference & $p$ value \\
\hline 1 & Vero sarcosine-aniline hybrid VS vero chloroquine & -7.78 & $0.006^{*}$ \\
\hline 2 & Vero sarcosine-aniline hybrid VS vero artesunate & 30.48 & $p \leq 0.001^{*}$ \\
\hline 3 & Vero sarcosine-aniline hybrid VS vero doxorubicin & 48.21 & $p \leq 0.001^{*}$ \\
\hline
\end{tabular}

\section{Discussion}

4.1. Sarcosine-Aniline Hybridization. In this study, the two molecules were used to synthesize a hybrid: 3-chloro-4-(4chlorophenoxy) aniline and sarcosine. The molecular purity of 3-chloro-4-(4-chlorophenoxy) aniline and sarcosine was $97 \%$ and $98 \%$, respectively, as confirmed by the manufacturer labels upon their delivery in Kenya by Sigma Aldrich. The sarcosine was completely soluble in water, but the solubility of 3-chloro-4-(4-chlorophenoxy) aniline and the hybrid in water was very low. They were soluble in dimethyl sulfoxide (DMSO) and slightly soluble in Tween 80 . It is clear that the low solubility of sarcosine-aniline hybrid affected the drug absorption, distribution, and its metabolism. Confirmed by thin layer chromatography, the hybrid (was successfully synthesized using 3-Chloro-4-(4-chlorophenoxy) aniline and sarcosine pharmacophores.

4.2. In Vivo Efficacy of Sarcosine-Aniline Hybrid. Results from this study showed that sarcosine-aniline hybrid drug has in vivo antimalarial activity. However, sarcosine when used singly was not having inhibition activity against $P$. berghei ANKA sensitive strain ( $\mathrm{ED}_{50}$ not detectable). This was due to different reasons, such as sarcosine being transformed into glycine by glycine-N-methyl transferase enzyme. The $\mathrm{ED}_{50}$ of sarcosine-aniline hybrid drug was $6.49 \mathrm{mg} / \mathrm{kg}$, whereas that of 3-chloro-4-(4-chlorophenoxy) aniline alone was $3.61 \mathrm{mg} / \mathrm{kg}$. There was a significant difference between ED50 of sarcosine-aniline hybrid and both controls such as 3-chloro-4-(4-chlorophenoxy) aniline, artesunate, artesunate-aniline hybrid drug, and chloroquine. On the hand, there was no significant difference between $\mathrm{ED}_{50}$ of artesunate-aniline hybrid drug and 3-chloro-4-(4chlorophenoxy) aniline as well as between 3-chloro-4-(4chlorophenoxy) aniline and artesunate. In the study carried out on in vivo antiplasmodial potentials of the combinations of four Nigerian antimalarial plant extracts, the $\mathrm{ED}_{50}$ of $\mathrm{CQ}$ using the oral administration pathway was $2.2 \mathrm{mg} / \mathrm{kg}$ [22], and this is in agreement with the current study, where the $\mathrm{ED}_{50}$ of chloroquine was $1.78 \mathrm{mg} / \mathrm{kg}$.

The in vivo activity of sarcosine-aniline hybrid drug was less than that of other control drugs used in this study. This may be due to other conversions of the hybrid drug which may occur along the oral administration pathway such as in the bowels. As a result, this can prevent hybrid molecules from reaching the target sites. The type of the drug administration method for effectiveness of a drug can also be of a great concern. Therefore, if sarcosine-aniline hybrid drug can be administered intravenously or subcutaneously, it might also improve its efficacy and its bioavailability. It is known that artesunate has a shorter half-life, and its combination with other drugs increases its bioavailability. The half-life of both 3-chloro-4-(4-chlorophenoxy) aniline and sarcosine is not yet known to determine their stability while combined or hybridized with other compound or drugs. Artesunate-aniline hybrid drug was active compared with both 3-chloro-4-(4-chlorophenoxy) aniline and artesunate when used singly. This might be because artesunate is a semisynthetic derivative of artemisinin whose water solubility facilitates absorption and provides an advantage over other artemisinins. In addition, artesunate is rapidly hydrolyzed to dihydroartemisinin, which is the most active schizonticidal metabolite [23]. By contrast, 3-chloro-4-(4chlorophenoxy) aniline being a low water-soluble compound might affect the artesunate solubility in the resultant hybrid drug.

In a study on potent in vivo antimalarial activity and representative snapshot pharmacokinetic evaluation of artemisinin-quinoline hybrid, the three synthesized artemisinin-quinoline hybrids differed from each other by one methyl group in the linker and position in the chain; their $\mathrm{ED}_{50}$ were $1.1,1.4$, and $<0.8 \mathrm{mg} / \mathrm{kg}$, respectively, using the intraperitoneal route and 12,16 , and $13 \mathrm{mg} / \mathrm{kg}$, respectively, using the oral route [24]. The $\mathrm{ED}_{50}$ of artesunate was $1.8 \mathrm{mg} / \mathrm{kg}$ using the oral route with $80 \mathrm{mg} / \mathrm{kg}$ as highest dosage, and it was $<1 \mathrm{mg} / \mathrm{kg}$ using the intraperitoneal route [24]; these results differ slightly with results of this study because of the dosages and methods used, in current study, and no intraperitoneal method was used rather than the oral method. In another study on oral artesunate dose-response relationship in acute falciparum malaria, the effective doses were determined after treating patients from whom the infections were detected with a dose varying from 0 to $250 \mathrm{mg}$ of artesunate together with a curative dose of mefloquine; the resultant $\mathrm{ED}_{50}$ was $1.6 \mathrm{mg} / \mathrm{kg}$ [25], and this result differs with the current study as the artesunate here was combined with mefloquine, and the study used patients, whereas in this study, P. berghei was administered in mice.

The percentage of chemosupression for sarcosine-aniline hybrid was around 55\%, whereas that of aniline was $68 \%$, the percentage of chemosupression was $100 \%$ for mice treated with $10 \mathrm{mg} / \mathrm{kg}$ of artesunate and chloroquine. However, there was a recrudescence after 5 days post-treatment for 
both mice treated with artesunate and chloroquine, whereas for other drugs, there was a continuous increase in the parasitaemia after stopping the treatment (Table 2). The recrudescence in mice treated with artesunate and chloroquine might be due to some remnant parasites which survived after stopping the treatment. In the study on antimalarial activity of methanolic leaf extract of Piper betle L, there was $100 \%$ chemosupression for the mice treated with chloroquine with $20 \mathrm{mg} / \mathrm{kg}$ using the oral route [26], which agrees with the current study, where the percentage of chemosupression was $100 \%$ at day 4 following oral treatment at $10 \mathrm{mg} / \mathrm{kg}$.

The number of mice which survived up to 11 days of experiment during in vivo efficacy testing was recorded. Actually, after 7 days when the drug administration was stopped, the number of mice which were still alive was different according to the type of drug and its dosage. This is because at this dosage, there was a $100 \%$ of parasite growth inhibition. According to the current study, there was where the low drug dosage showed a high number of survived mice compared with the higher dosage concentration of the same drug.

4.3. In Vitro Toxicity of Sarcosine-Aniline Hybrid. In-vitro toxicity tests are the alternative method approaches to animal acute toxicity evaluation. Vero cell lines are usually used in prospective studies to determine the cytotoxic effect of different natural and artificial products [27]. Cytotoxicity results from this study showed that the hybrid drug was safe to vero cells. When compared with other standard drugs, sarcosine-aniline hybrid was significantly less toxic compared with artesunate. There was also a significant difference between cytotoxicity of hybrid drug and that of CQ against mammalian cell lines. In the study on effects of chloroquine to inhibit dengue virus type 2 replication in vero cells but not in C6/36 cells, the concentrations equal or greater than $500 \mu \mathrm{g} / \mathrm{ml}$ showed major cytotoxicity but the concentrations equal or lesser than $50 \mu \mathrm{g} / \mathrm{ml}$ did not reveal cytotoxicity effects on vero cells [28]. These results agree with the current study, where the $\mathrm{CC}_{50}$ of chloroquine was $57.96 \mu \mathrm{g} / \mathrm{ml}$.

Therefore, the side effects caused by CQ such as neurotoxicity, leukopenia, retinopathy, and cardiovascular toxicity might be absent, reduced, or increased for sarcosineaniline hybrid drug, but this requires chronic toxicity to be performed using mice so that blood parameters and histopathology of liver, kidney, heart, and brain dysfunction might be elucidated. Doxorubicin was significantly more toxic than hybrid drug to vero cells. Doxorubicin served as a control in cytotoxicity studies as it was revealed that it is more toxic to cancerous cells and even to normal cells including vero cells which had been used in this study. Doxorubicin's cytotoxicity is based on its capacity to bind to DNA-associated enzymes (topoisomerases), intercalate with DNA base pairs, and target multiple molecular targets to produce a wide range of cytotoxic effects. It also activates the Bcl-2/Bax apoptosis pathway when it interacts with cells' membranes [29].
4.4. Acute Toxicity of Sarcosine-Aniline Hybrid. Acute toxicity showed that the hybrid drug was safe to mice. There was no dead mice observed with $2000 \mathrm{mg} / \mathrm{kg}$, so the $\mathrm{LD}_{50}$ is expected to be above $5000 \mathrm{mg} / \mathrm{kg}$; thus, this drug is classified in category 5 according to the OECD/OCDE guideline for testing chemical compounds [30]. The weights measured during acute toxicity testing showed that the weight loss was observed in the first week of experiment and increased in the second week of experiment for the group which received $2000 \mathrm{mg} / \mathrm{kg}$ and $300 \mathrm{mg} / \mathrm{kg}$. There was a continuous gain in weights for the group which received a single dose of $50 \mathrm{mg} / \mathrm{kg}$ and control group. There was no significant difference in weights within and between groups at the end of acute toxicity experiment. No clinical physical signs of discomfort such as impaired ambulation, excessive weight loss, lack of physical or mental alertness, difficulty breathing, prolonged inability to remain upright, and extreme emaciation observed during acute toxicity experiment. The therapeutic index of a drug is the ratio that compares the blood level concentrations at which a given drug is toxic (lethal dose) and the concentration at which the drug is effective (effective dose), which is a vital criterion for drug selection [31].

The therapeutic index of sarcosine-aniline hybrid drug is greater than 770.41, which confirms its safety as the concentration required to cause toxicity $(>5000 \mathrm{mg} / \mathrm{kg}$ ) is far greater than that of required to kill parasites $(6.49 \mathrm{mg} / \mathrm{kg})$ [32]. The closer the TI is to 1 , the more dangerous is, and the larger the therapeutic index (TI), the safer the drug is [32]. In fact, if the TI is small, the drug might be dosed thoroughly, and the patient receiving the drug should be monitored carefully for any clinical signs of drug toxicity [32]. The study by Xie et al. [31] on new potential antimalarial agents: Therapeutic-index evaluation of pyrroloquinazolinediamine and its prodrugs in a rat model of severe malaria; the therapeutic index of artesunate was 4 [31]. When comparing the results from Xie et al. [31], the therapeutic index of sarcosine-aniline hybrid is 192.6-fold greater than that of artesunate, which implies that the sarcosine-aniline hybrid is safer than artesunate.

\section{Conclusions}

Sarcosine-aniline hybrid has been synthesized using sarcosine and 3-chloro-4-(4-chlorophenoxy) aniline pharmacophores, and the product formation was monitored and confirmed by thin layer chromatography. Sarcosine-aniline hybrid drug is a promising antiplasmodial prodrug as it showed activity for in vitro and in vivo studies with an IC50 of $44.80 \pm 4.70 \mathrm{ng} / \mathrm{ml}$ and an $\mathrm{ED}_{50}$ of $6.49 \mathrm{mg} / \mathrm{kg}$, which are within acceptable ranges of drugs used to treat severe malaria [1]. This study points out that sarcosine-aniline hybrid drug is safe to vero cells with a $\mathrm{CC}_{50}$ of $50.18 \pm 3.53 \mu \mathrm{g} / \mathrm{ml}$ compared with doxorubicin which is most toxic with a $\mathrm{CC}_{50}$ of $1.96 \pm 0.59 \mu \mathrm{g} / \mathrm{ml}$. The acute toxicity results showed no dead mice up to the dosage of $2000 \mathrm{mg} / \mathrm{kg}$ using oral administration for 14 days, and there was no significant loss of weight in mice within and 
between groups with different dosages of sarcosine-aniline hybrid as well as in the control group. There should be the use of covalent bitherapy in drug development. The use of covalent biotherapy in drug resistance mitigation is recommended.

\section{Abbreviations}

ACT: Artemisinin combination therapy

Aniline: 3-chloro-4-(4-chlorophenoxy) aniline

ATCase: Aspartate carbomyl transferase

$\mathrm{CC}_{50}$ : Cytotoxicity concentration at $50 \%$

CDC: $\quad$ Center for disease control and prevention

CPM: $\quad$ Counts per minute

CQ: $\quad$ Chloroquine

DMSO: Dimethyl sulfoxide

DNA: Deoxyribonucleic acid

ED50: $\quad$ Effective dose at 50\%

ENR: Enoyl acyl carrier protein reductase

GM: Geometric mean

$\mathrm{IC}_{50}: \quad 50 \%$ inhibitory concentration

IP: Intraperitoneal

$\mathrm{IC}_{50}$ : Inhibition concentration at $50 \%$

JKUAT: Jomo Kenyatta University of Agriculture and Technology

KEMRI: Kenya Medical Research Institute

MKU: $\quad$ Mount Kenya University

MTT: 3-(4,5-dimethylthiazol-2-yl)-2,5diphenyltetrazolium bromide

MEM: $\quad$ Minimum Essential Eagle's Medium

OD: Optical density

OECD: Organization for Economic Co-operation and Development

PAUSTI: Pan African University, Institute of Basic Sciences Technology and Innovation

P. $f \quad$ P. falciparum sarco-endoplasmic reticulum

ATPase: calcium ATPase

P. $f$ ENR: Enoyl acyl carrier protein reductase

PMI: $\quad$ President's malaria initiative

RBCs: $\quad$ Red blood cells

SERU: Scientific and Ethics Review Unit

WHO: World Health Organization.

\section{Data Availability}

All materials and data used to support the findings of this study are available from the corresponding author upon request.

\section{Ethical Approval}

Handling of animals was done in accordance to the KEMRI Guide for Care and Use of Laboratory animals. Ethical clearance was sought from Scientific Ethic Review Unit (SERU), in KEMRI (Protocol number: KEMRI/SERU/ CBRD/PROP155/3324). Mice were handled with a lot of care as stipulated in guidelines set by KEMRI Animal Care and Use Committee (Ref Number: KEMRI/CBRD/MP/AH/01).

\section{Disclosure}

This paper was presented in the 3rd Africa International Biotechnology and Biomedical Conference (AIBBC). This work was also presented in the Joint 5th SASA International Conference and 2nd Rwanda Biotechnology Conference and in 2nd World Congress and Expo on Biotechnology and Bioengineering. The draft version of this paper was prepublished on preprints. org > doi: 10.20944/preprints201911. 0104.v1.

\section{Conflicts of Interest}

The authors declare no conflicts of interest.

\section{Authors' Contributions}

JBN conducted in vitro and in vivo experiments and drafted the manuscript. FO, PGK, and JBN worked together to synthesize the hybrid molecule. KF provided the facilities for in vitro testing. JKN and PGK revised the work and approved it. All authors have read and approved the manuscript.

\section{Acknowledgments}

The authors are grateful to the Kenya Medical Research Institute and Mount Kenya University for providing some crucial facilities during laboratory work. This project was funded by the African Union (AU) through Pan African University, Institute of basic sciences and Innovation and Kenya Medical Research Institute (KEMRI). AU funded in the design of the study, data collection, sample analysis, interpretation of data, and writing the manuscript. KEMRI provided the facilities for experimental testing. The authors are grateful to Muthuri Njoka and Chrispus Ngule Mutuku, research associates at KEMRI, for their assistance in experimentations during this study.

\section{References}

[1] WHO, "Malaria," 2018, https://www.who.int/gho/malaria/en/ in2018.

[2] R. W. Snow, C. A. Guerra, A. M. Noor, H. Y. Myint, and S. I. Hay, "The global distribution of clinical episodes of Plasmodium falciparum malaria," Nature, vol. 434, no. 7030, pp. 214-217, 2005.

[3] P. J. Rosenthal, "Antimalarial drug discovery: old and new approaches," Journal of Experimental Biology, vol. 206, no. 21, pp. 3735-3744, 2003.

[4] CDC, About Malaria Biology Malaria Parasites, CDC, Atlanta, GA, USA, 2015.

[5] A. Saifi, T. Beg, A. H. Harrath, F. Suleman, H. Altayalan, and S. A. Quraishy, "Antimalarial drugs: mode of action and status of resistance," African Journal of Pharmacy and Pharmacology, vol. 7, no. 5, pp. 148-156, 2013.

[6] T. N. C. Wells, R. H. van Huijsduijnen, and W. C. Van Voorhis, "Malaria medicines: a glass half full?" Nature Reviews Drug Discovery, vol. 14, no. 6, pp. 424-442, 2015.

[7] J. E. Cronan and T. R. Massengo, "Diversity in enoyl-acyl carrier protein reductases," Cellular and Molecular Life Sciences, vol. 66, no. 9, pp. 1507-1517, 2009. 
[8] B. Hay, C. F. Poole, and C. Weins, Quantitative Thin-Layer Chromatography (TLC), Springer, Berlin, Germany, 2011.

[9] A. Widyawaruyanti, M. Asrory, W. Ekasaria et al., "In vivo Antimalarial Activity of Andrographis paniculata tablets," Procedia Chemistry, vol. 13, pp. 101-104, 2014.

[10] H. Noedl, C. Wongsrichanalai, and W. H. Wernsdorfer, "Malaria drug-sensitivity testing: new assays, new perspectives," Trends in Parasitology, vol. 19, no. 4, pp. 175-181, 2003.

[11] R. E. Desjardins, C. J. Canfield, J. D. Haynes, and J. D. Chulay, "Quantitative assessment of antimalarial activity in vitro by a semiautomated microdilution technique," Antimicrobial Agents and Chemotherapy, vol. 16, no. 6, pp. 710-718, 1979.

[12] B. Kalra, S. Chawla, P. Gupta, and N. Valecha, "Screening of antimalarial drugs: an overview," Indian Journal of Pharmacology, vol. 38, no. 1, p. 5, 2006.

[13] D. A. Fidock, P. J. Rosenthal, S. L. Croft, R. Brun, and S. Nwaka, "Antimalarial drug discovery: efficacy models for compound screening," Nature Reviews Drug Discovery, vol. 3, no. 6, pp. 509-520, 2004.

[14] P. Jeruto, R. M. Nyangacha, and C. Mutai, "In vitro and in vivo antiplasmodial activity of extracts of selected Kenyan medicinal plants," African Journal of Pharmacy and Pharmacology, vol. 9, no. 16, pp. 500-505, 2015.

[15] S. Reagan-Shaw, M. Nihal, and N. Ahmad, "Dose translation from animal to human studies Revisited," Journal of the Federation of American Society for Experimental Biology, vol. 22, no. 3, pp. 659-661, 2007.

[16] Research Animal Resources Center, "Calculating injection doses for rodents," 2016, https://www.rarc.wisc.edu/animal_ health/experimental_techniques/calculating_injection_dose_ rodent.html.

[17] W. Peters, J. H. Portus, and B. L. Robinson, "The chemotherapy of rodent malaria, XXII," Annals of Tropical Medicine \& Parasitology, vol. 69, no. 2, pp. 155-171, 1975.

[18] T. L. Riss, R. A. Moravec, A. L. Niles et al., Assay Guidance Manual. Cell Viability Assays, Bethesda, Eli Lilly \& Company and the National Center for Advancing Translational Sciences, Rockville, MD, USA, 2016.

[19] T. Mosmann, "Rapid colometric assay for cellular growth and survival: application to proliferation and cytotoxicity assays," Journal of Immunological Methods, vol. 65, no. 1-2, pp. 55-63, 1983.

[20] P. A. Tarkang, K. Diehl Franzoi, S. Lee et al., "In vitro antiplasmodial activities and synergistic combinations of differential solvent extracts of the polyherbal product, Nefang," BioMed Research International, vol. 2014, Article ID 835013, 10 pages, 2014.

[21] Engineering, D. natural sciences. (n.d.), In vitro determination. https://www.who.int/tdr/grants/workplans/en/cytotoxicity_invitro. pdf, 2017.

[22] A. Adebajo, S. Odediran, F. Aliyu, P. Nwafor, N. Nwoko, and U. Umana, "In vivo antiplasmodial potentials of the combinations of four Nigerian antimalarial plants," Molecules, vol. 19, no. 9, pp. 13136-13146, 2014.

[23] Q. Li and P. Weina, "Artesunate: the best drug in the treatment of severe and complicated malaria," Pharmaceuticals, vol. 3, no. 7, pp. 2322-2332, 2010.

[24] M. C. Lombard, D. D. N’Da, C. Tran Van Ba et al., "Potent in vivo anti-malarial activity and representative snapshot pharmacokinetic evaluation of artemisinin-quinoline hybrids," Malaria Journal, vol. 12, no. 1, p. 71, 2013.

[25] B. J. Angus, I. Thaiaporn, K. Chanthapadith, Y. Suputtamongkol, and N. J. White, "Oral artesunate doseresponse relationship in acute Falciparum malaria,"
Antimicrobial Agents and Chemotherapy, vol. 46, no. 3, pp. $778-782,2002$.

[26] A.-H. Al-Adhroey, Z. M. Nor, H.-M. Al-Mekhlafi, A. A. Amran, and R. Mahmud, "Antimalarial activity of methanolic leaf extract of Piper betle L," Molecules, vol. 16, no. 1, pp. 107-118, 2010.

[27] C. Menezes, E. Valério, and E. Dias, "New insights into toxicity and drug testing," in The Kidney Vero-E6 Cell Line: A Suitable Model to Study the Toxicity of Microcystins, Biology and Ecotoxicology Laboratory, Environmental Health Department, National Health Institute Dr. Ricardo Jorge, Lisbon, Portugal, 1st edition, 2013.

[28] K. J. S. Farias, P. R. L. Machado, and B. A. L. da Fonseca, "Chloroquine inhibits dengue virus type 2 replication in vero cells but not in C6/36 cells," The Scientific World Journal, vol. 2013, Article ID 282734, 5 pages, 2013.

[29] O. Tacar, P. Sriamornsak, and C. R. Dass, "Doxorubicin: an update on anticancer molecular action, toxicity and novel drug delivery systems," Journal of Pharmacy and Pharmacology, vol. 65, pp. 157-170, 2013.

[30] OECD/OCDE, "OECD guideline for testing of chemicals," 2001, https://ntp.niehs.nih.gov/iccvam/suppdocs/feddocs/ oecd/oecd_gl423.pdf.

[31] L. H. Xie, Q. Li, A. J. Lin, K. Smith, J. Zhang, and D. S. Skillman, "New potential antimalarial agents: therapeutic-index evaluation of pyrroloquinazolinediamine and its prodrugs in a rat model of severe malaria," Antimicrobial Agents and Chemotherapy, vol. 50, no. 5, pp. 1649-1655, 2006.

[32] P. Y. Muller and M. N. Milton, "The determination and interpretation of the therapeutic index in drug development," Nature Reviews Drug Discovery, vol. 11, no. 10, pp. 751-761, 2012. 